\title{
An exploration of an integrated counselling and coaching approach with distressed young people
}

\author{
Alan T. Flynn, Nicola L. Sharp, James J. Walsh and Nash Popovic \\ School of Psychology, University of East London, London, U.K.
}

Word count: 9,525 (including tables, figures, captions, references, endnotes and footnotes).

Correspondence should be addressed to Nash Popovic, University of East London, Water Lane, Stratford, London, E15 4LZ, UK (email: n.popovic@uel.ac.uk)

Notes on contributors (telephone numbers, email addresses, ORCiDs)

Alan T. Flynn is currently a second year trainee on the Professional Doctorate in Counselling Psychology (DPsych) programme at the University of East London. He obtained an MSc in Psychology from the University of East London in 2015. (07580 808749, u1426788@,uel.ac.uk, orcid.org/0000-0002-6934-1431)

Nicola L. Sharp is currently a psychotherapist in private practice. She obtained a MA in Counselling and Psychotherapy from the University of East London in 2016. (07850 850602, nicolasharp7@gmail.com, orcid.org/0000-0003-3763-4333)

James J. Walsh is a principal lecturer at the University of East London. (020 8223 4471, j.j.walsh@uel.ac.uk)

Nash Popovic is a senior lecturer and program leader in integrative counselling and coaching at the University of East London. He is also a Personal Consultant in private practice and cofounder of Personal Wellbeing Center as well as co-author of Personal Consultancy: a model for integrating Counselling and Coaching. (07491 053936, n.popovic@uel.ac.uk) 


\section{An exploration of an integrated counselling and coaching approach with distressed young people}

This mixed-methods study explored the effectiveness and experience of an integrated counselling and coaching approach with young people. An effectiveness study allocated 80 young people aged between 13 and 25 years from four Youth Information Advice and Counselling Services (YIACS) centres in England to two groups: an integrated counselling and coaching group, based on the Personal Consultancy (PC) model, and a humanistic counselling group. Self-report measures of distress were administered at baseline and endpoint. Findings of the quantitative analysis showed that although baseline distress levels between groups were equivalent, post-intervention levels were significantly lower in the integrated group. Interpretative Phenomenological Analysis (IPA) of qualitative experiences from five young people from the integrated group explored possible reasons for these results. Five master themes emerged: making sense of past, present and/or future, developing a sense of agency, management of affect, enhancing interpersonal relationships and development of self. Findings indicated that young people responded well to the integrated treatment; attending to intra-psychic issues alongside their developmental challenges seemed to have a beneficial effect on their sense of agency in particular. In conclusion, $\mathrm{PC}$ may be an effective means of reducing distress in young people.

Keywords: counselling; coaching; personal consultancy; psychological distress; young people 
The latest published survey indicates that one in ten 5-16 year olds in Great Britain suffers from a diagnosable mental health disorder (Children's Society, 2008) and half of nearly all lifelong mental illnesses have begun by age 14 (Kessler et al., 2005, 2007; Kim-Cohen et al., 2003). While a new survey on child and adolescent mental health is currently taking place (Office for National Statistics [ONS], 2016), there is very little reason to think that observed levels of psychopathology will diminish. Indeed, current referral rates for support with mental health issues for young people suggest that an increase in incidence is more likely to be detected (House of Commons Health Committee, 2014; Nuffield Foundation, 2013).

Young people who seek help specifically for psychological problems also have to deal with a variety of other developmental issues. In the process of becoming a selfgoverning adult, a number of challenges must be faced. These include, for example, making initial career plans, developing skills for independent living, creating new and often intimate relationships, coping with peer pressure, dealing with bureaucracies and so forth (Street, 2014; Youth Access, 2015). The challenge for mental health practitioners therefore is how best to support young people to address their psychological problems, as well as these social and developmental issues, simultaneously. While traditional counselling for young people produces impressive results (Cooper, 2009; Cooper, Pybis, Hill, Jones, \& Cromarty, 2013), client feedback consistently suggests a preference for a more proactive and goal-oriented approach (Geldard \& Geldard, 2010; Lynass, Pykhtina \& Cooper, 2012; Mumby, 2011; Westergaard, 2013). Coaching constitutes just such an approach and the British Association of Counselling and Psychotherapy (BACP, 2016) recently placed coaching towards the latter end of a therapeutic/developmental continuum. Whilst there is a contested debate regarding their definitions (Griffiths \& Campbell, 2008; Spinelli, 2008), coaching is generally regarded as a more proactive approach compared with traditional models of counselling in terms of 
achieving behavioural modification (Giant, 2014; Mumby, 2014; Popovic \& Jinks, 2014). Using interventions that are typically developmental in nature (BACP, 2016), coaching seeks to initiate change in a more focused manner than counselling or psychotherapy by specifically defining clients' goals and the means to achieve them (Mumby, 2011; Popovic \& Boniwell, 2007). Such interventions are more likely to "build on existing strengths, less likely to be accompanied by high levels of distress, and [are] driven by the client's desire to develop their potential, and/or understanding of themselves, their beliefs, behaviours and actions" (BACP, 2016). While this may hold true to some extent for counselling, coaching is typically more present-future oriented (Griffiths \& Campbell, 2008) while counselling is typically more focused on the present and the past (Pointon, 2003; Popovic \& Boniwell, 2007; Williams, 2003).

Berg and Steiner (2003) claim that young people tend to address their difficulties by looking ahead to the future. Therefore, adding coaching skills (with their emphasis on the future) to traditional counselling may provide a better fit with young people's preferred methods of dealing with their issues. The theoretical rationale for the benefits of techniques associated with coaching in one-to-one work with young people has received empirical support (Cooper, 2004; Williams, 2003). For example, increases in cognitive hardiness, hope and agency were found after using a coaching intervention with high school students (Green, Grant \& Rynsaardt, 2007). Increased hope and improved examination performance were observed following behavioural goal-focused coaching in a study by Passmore and Brown (2009). Coaching has rarely been offered in schools though, most likely because it is not well equipped to also address issues of a deeper psychological nature (Bachkirova \& Cox, 2004). These deep-rooted issues, Mumby (2014) proposed, can be explored by integrating coaching with counselling, thereby enabling the client to pursue developmental and 
therapeutic work with the same practitioner.

The possibility of integrating counselling and coaching evokes the often-vexed question of boundaries. According to Popovic and Boniwell (2007), counselling is usually associated with a more non-directive, reactive and diffuse approach and is concerned with existing emotional, cognitive and behavioural patterns, whereas coaching is typically associated with a more directive, proactive and focused approach and concerned with desired and strived-for patterns. However, many practitioners and researchers suggest that the boundaries between the two are blurred and somewhat artificial (Buckley, 2007; Maxwell, 2009; Patrick, 2015; Popovic \& Boniwell, 2007; Simons, 2006). In fact, some counselling approaches that are proactive and focused on the future, such as Solution Focused Therapy (SFT) and Cognitive Behaviour Therapy (CBT), could be considered closer to coaching than to other counselling approaches (such as Humanistic or Psychodynamic ones, for example). With full recognition of this complexity, for the purposes of this paper we take coaching to be more goal-orientated and focused on external matters, and counselling to be more focused on the client's internal experience.

The Personal Consultancy (PC) model of integration (Popovic \& Jinks, 2014) that is used in this study is neither a coaching nor a counselling model but rather seeks to integrate skills from a variety of counselling approaches as well as coaching. PC offers practitioners the opportunity to work with intra-psychic processes as well as help the client to make practical changes and achieve tangible goals. It is hypothesised that flexibly alternating between modes of 'being with' the client (e.g. non-directive, reactive and diffuse mode) and 'doing with' the client (e.g. more directive, proactive and focused mode), and switching between existing patterns and emerging patterns, may enhance the efficacy of the one-to-one process (Popovic \& Jinks, 2014). 
In contrast to many other integrated models, PC is a demarcated approach (Popovic \& Jinks, 2014). It utilizes traditional components of counselling and coaching successively and distinctively, as opposed to eclectic or fused ways of doing so where there might exist no clear distinction between constitutive elements (such as CBT). The PC framework achieves this demarcation by proposing four stages of the PC model. Some of these stages utilise traditional counselling skills while others focus more on skills from coaching and other proactive counselling approaches (e.g. SFT). At the beginning of sessions the clients are shown the PC model and the possibility of moving between different stages and modes of working is highlighted. When these occur during one-to-one collaborative work they are made explicit by the therapist.

Mumby $(2011,2014)$ offers adaptations of the stages of the PC model that are better suited for working with young people. Figure 1 presents the dimensions and stages of the PC model in a youth friendly version.

Insert Figure 1

about here

The four stages of the PC approach with young people are termed (a) Being heard, (b) Finding your balance, (c) Moving forward and (d) Supporting (Mumby, 2014). The first stage involves listening authentically to clients to hear their thoughts and feelings about their situation and to identify what it is that they would like to work on. Stage two helps clients to identify their strengths and areas for development in the cognitive, emotional and behavioural 
domains. Stage three involves moving away from unhelpful or destructive existing patterns and employs coaching techniques such as 'visualisation, making decisions, forming goals and testing solutions' in order to explore new options (Mumby, 2014, p.147). Finally, the practitioner supports clients throughout the process and in identifying alternative support from friends, family and others for when the formal sessions are over.

The first and the last stages are associated with 'being with' the client and the middle ones involve 'doing with' the client. These stages are not necessarily intended to be worked through in a linear sequence (Popovic \& Jinks, 2014). After each stage it may be necessary to revisit the 'Being heard' stage to ensure that the client can process what has occurred in other stages and to ensure that the quality of the relationship is maintained. In addition, not all stages may be necessary for every client. Although there is some overlap, 'Finding your balance' stage can be closely associated with using counselling skills while the 'Moving Forward' stage mostly utilises skills from coaching and other goal-orientated one-to-one practices. This indicates that counselling and coaching skills are generally used at different stages of the process, rather than eclectically. For example, if the Personal Consultant works with a client whose issue is alcohol or drug addiction, in the 'Finding your balance' stage the Personal Consultant would explore possible underlying reasons and internal processes that may have led to the addiction. In the 'Moving forward' stage, the Personal Consultant would use coaching skills and some other proactive skills from approaches such as CBT and SFT to help the client to manage the habit itself and bring about a tangible behavioural change in this respect (cessation or reduction of use of alcohol or drugs). In the first stages of the model - 'Being heard' and 'Finding your balance' - the emphasis is on the relationship and internal processes, while in the 'Moving forward' and 'Supporting' stage the emphasis is on goal setting and achieving lasting behavioural modifications.

As highlighted above, PC is an integrated approach that may be suited to meeting 
young people's reparative as well as developmental needs. There is currently no research on PC or the integration of counselling and coaching with young people. The purpose of this mixed-methods study is to address the lack of quantitative and qualitative research in this area and is pragmatically designed, based on research opportunities that presented themselves in a postgraduate context. It seeks to investigate the effectiveness of an integrated counselling and coaching approach with young people in a naturalistic setting and to explore their experiences of this intervention. It was hypothesized that young people in the integrated group would show greater improvement in levels of self-reported distress than comparable individuals in a counselling-only condition.

\section{Method}

\section{Design}

A quantitatively-driven mixed-methods design was employed to assess both the effectiveness of the integrated counselling and coaching approach (PC) in dealing with young people's distress compared with a counselling-only treatment, and the participants' subjective experience of this intervention. Experimental methods were used to explore the comparative effectiveness of the interventions. As this was the first study of the PC intervention, it was particularly important to gain insight into the participants' accounts of the integrated intervention. Interpretative Phenomenological Analysis (IPA) was selected as a uniquely appropriate form of qualitative inquiry for analysing such accounts, as it aims to explore in detail participants' personal experiences or lifeworld (Smith \& Osborn, 2003).

The quantitative arm comprised of two independent variables, each incorporating two levels. The between-participants factor was type of intervention: standard counselling rooted in the humanistic modality or counselling and coaching combined; the within-participants factor was time: pre-intervention and post-intervention. Given the demarcated approach of 
PC, referred to above, practitioners who already combined approaches, such as personcentred and CBT, were not included in the counselling-only group. Levels of psychological distress constituted the dependent variable. The study was conducted across four voluntary and community sector Youth Information Advice and Counselling Service (YIACS)1 providers in England between January 2015 and July 2015. Each provider was autonomous in its service which it delivered free of charge to people aged between 11 and 25 years. The qualitative arm comprised of five interviews with participants who underwent the counselling and coaching intervention.

\section{Interventions}

Prior to the study, eleven counsellors from the YIACS agencies undertook a five-day training programme that introduced them firstly to coaching approaches and then to the PC model (Popovic \& Jinks, 2014). The focus of the training was on developing their coaching skills in order to complement their counselling experience. Various frameworks, tools and questions, designed to help young people map out their strengths, achievements and challenges, were explored. Considerable emphasis was placed upon what young people would like to change, what could be changed and, given their comparatively lower levels of autonomy than adults, what could not be changed. Developing strategies for helping young people to cope with the latter was also part of the training. While attention to goals and the actions needed to achieve

\footnotetext{
1 Each centre was in membership with Youth Access, the national membership organisation for young people's YIACS. YIACS provide a holistic response to young people's social, emotional and mental health needs through a range of services provided 'under one roof', including social welfare advice, advocacy, counselling, health clinics, community education and personal support (Youth Access, 2016).
} 
them is a key feature of coaching, working integratively ensures that the internal conflicts of clients are addressed too.

The active control intervention, comprised of humanistic counselling, was aimed at helping clients to explore their own thoughts and feelings and to work out their own solutions to their problems. The standard offer of humanistic counselling at each of the agencies and any potential variation in its delivery were not audited in great detail. The integrated intervention comprised of using the PC model as described above. The basics of the PC model were explained to the participants using a visual aid and it was discussed with the client throughout the work.

\section{Participants}

Participants were eligible for inclusion in the study if, at baseline assessment, they were: (a) aged at least 11 years; (b) experiencing moderate to high levels of psychological distress; (c) regarded as capable of providing informed consent; and (d) not at serious risk of harm to self or others. Eighty-five participants went through the standard assessment protocol in the different agencies. Five participants assigned to the counselling-only condition did not attend therapy subsequent to their assessment; however, their data were included in an intention-totreat analysis (Shaya \& Gu, 2007). Of the 85 participants, 55 were female $(64.7 \%)$ and the mean age was 16.6 years $(\mathrm{SD}=3.48$; range $=11$ to 25 years $)$. The mean number of sessions attended was $7.11(\mathrm{SD}=4.48$; maximum $=19)$. Data on participants' ethnic origin, disability or presenting issues were not available. Four females and one male, aged 13-16 years and representing three of the four YIACS centres, volunteered to be interviewed for the qualitative research. The intention was to include 8 participants in the qualitative research $(2$ participants from each of the YIACS centres), however 3 participants dropped out of the research before the interviews were conducted. 


\section{Measures}

CORE-10

The CORE-10 (Connell \& Barkham, 2007) is a brief measure of self-reported distress that comprises of 10 items from the original Clinical Outcomes in Routine Evaluation Outcomes Measure (CORE-OM; Evans et al., 2000). It assesses individuals' levels of depression, anxiety, general functioning, interpersonal relationships and risk of self-harm during the previous week. Items include, I have felt tense, anxious or nervous; I have felt able to cope when things go wrong $(R)$. A five-point rating scale $(0=$ Not at all, $4=$ Most or all of the time) accompanies each item. Two items require reverse scoring and total scores can range from zero to 40 . Scores of 11 or greater are believed to be in the clinical range; those of 15 to 19 represent moderate distress and those above 20 indicate moderate to severe distress. Scores above 25 represent severe distress. The measure has proved to be reliable (Cronbach's $\alpha=.90$; Barkham et al., 2013), and correlations of $r=.81$ with the Symptoms Checklist-90-R (Derogatis, 1994) and $\mathrm{r}=.77$ with the Beck Depression Inventory (Beck, 1978 ) attest to its validity (Evans et al., 2000). The practical nature of the measure for use in primary care settings for those with common mental health problems was noted by Barkham et al. (2013). In the current study, the CORE-10 was completed by young people aged 17 and above.

\section{Young Person's CORE (YP-CORE)}

The Young Person's CORE (YP-CORE) assesses psychological distress among 11 to 16 year olds (Twigg et al., 2009). It comprises of 10 items that, like the CORE-10, have their origins in the CORE-OM. The chosen items were carefully scrutinized for comprehension by the target age group while, at the same time, maintaining a balance of positive and negative items and sampling from a broad range of relevant domains (anxiety, depression, general 
functioning, interpersonal relationships and risk of self-harm). The measure asks young people to rate how they have been feeling over the past week on a five-point scale $(0=$ Not at all, $4=$ Most or all of the time). Items include, I've felt edgy or nervous; There's been someone I felt able to ask for help $(R)$. Ratings are summed to give an overall score from zero to 40, with higher scores indicating higher levels of psychological distress. The YPCORE has been shown to be acceptable to young people and to possess good internal consistency (Cronbach's $\alpha=.85$ ). It is the most widely used measure in school-based counselling services within the UK (Cooper, 2009).

\section{Procedure}

Ethical approval was obtained from relevant committees. Participants were provided with information about the study during their initial assessment and those who agreed to take part proceeded to complete baseline measures of distress using either the CORE-10 or the YPCORE, depending on their age. They were then allocated to one of two treatment groups: the integrated condition or the counselling-only condition. In some of the treatment locations therapists who had undertaken the PC training provided participants with a choice between interventions at the outset. Thus, some of the participants effectively self-selected into the PC intervention or the counselling-only intervention. Unfortunately, we were not able to fully ascertain the number of participants affected. We had designed the study so that allocation to treatment condition would be randomized but we were a couple of steps removed from the final decision point and this did not take place entirely as planned. We acknowledge the potential impact this had on the study in the discussion section.

Distress levels were re-assessed at the end of treatment using the same measures. Youth Access promoted the study and selected the four participating agencies based on their level of interest and capacity to release counsellors for initial training. They also sought to 
maximize geographical diversity and to include both urban and rural services. All one-to-one sessions were delivered by qualified (or in some cases minimum second-year trainees) counsellors who adhered to the codes of ethics and practice set by the British Association of Counselling and Psychotherapy and to the Youth Access Framework of Quality Standards.

Once the intervention was completed, semi-structured interviews with five young people from the integrated condition were carried out. The interviewer had no prior acquaintance with the participants. Four interviews were conducted in the school premises where participants received their sessions while, for logistical reasons, one took place via telephone. The interviews ranged from 18 to 40 minutes and were audio-recorded, transcribed verbatim, and analysed using IPA.

\section{Analyses}

\section{Quantitative data}

There is a very high degree of similarity between the 10 questionnaire items in the YP-CORE (completed by those aged 11 to 16 years) and those in the CORE-10 (completed by those aged 17 to 25 years). However, for analytical purposes overall scores on these questionnaires were standardized and both sets of standardized scores were amalgamated into a single variable prior to carrying out the 2 (intervention type: integrative v counselling-only) $\mathrm{x} 2$ (time: before $\mathrm{v}$ after intervention) intention-to-treat mixed ANOVA. To aid interpretation, non-standardized scores are presented in tables and figures. Descriptive and inferential statistics were carried out using SPSS version 23 (IBM).

\section{Qualitative data}

The six-step analytic process suggested by Smith, Flowers and Larkin (2009) was followed. Each interview was analysed independently to maintain an idiographic focus. Thorough reading and re-reading produced descriptive, linguistic and conceptual annotations of each 
transcript. Emerging themes were labelled for each participant and these themes were collated to form super-ordinate themes or categories, classifying them into groups of similarity. This process involved polarisation, contextualisation of data, and numeration, which helped to identify connections, similarities and differences within the participants' experiences. After all interviews had been analysed, a table was constructed to illustrate the frequency of super-ordinate and emergent themes across all interviews. A process of comparing, contrasting and combining super-ordinate themes led to the formation of master themes, categories of emergent themes that applied to all participants.

\section{Results}

\section{Quantitative findings}

Initial inspection of the data suggested that the gender composition of the integrated intervention condition [ $n=16$ males and 26 females] was similar to that of the counsellingonly condition [ $n=14$ males and 29 females]. This was subsequently confirmed via a 2 (gender) $\times 2$ (intervention condition) chi-square analysis $\left[\chi^{2}=0.29, d f=1, p=.593\right]$. The mean age of participants in the integrated condition $[M=14.93, S D=3.29]$ was lower than that in the counselling-only condition $[M=18.23, S D=2.84]$. An independent $t$ test indicated that this difference was statistically significant $[t(83)=4.96, p=.001]$. Age was therefore included as a covariate in the proposed 2 (time) $\times 2$ (intervention condition) intention-to-treat ANOVA. Finally, the mean number of sessions undertaken by those in the counselling group $(M=6.45 ; S D=4.54)$ was similar to the number undertaken by those in the integrated group $(M=7.78 ; S D=4.36)[t(83)=-1.37, p=.173]$.

Mean levels of distress, as assessed by scores on the CORE-10 (17-25 year olds) and YP-CORE (11-16 year olds), are presented in Table 1 below. It may be seen that, prior to intervention, young people were suffering from moderate-to-severe distress and that there 
were no obvious differences in distress levels between groups. Post intervention, participants in the integrated condition reported levels of distress that just exceeded the normative range while those in the counselling-only condition reported 'moderate' levels.

Insert Table 1

about here

In order to compare the integrated treatment provision with the standard counsellingonly treatment, a mixed 2 (intervention type: counselling-only v integrated) x 2 (time: baseline and endpoint) analysis of covariance was carried out with age as the covariate, time as the within-participant factor, treatment type as the between-participants factor, and distress levels from the CORE-10 and YP-CORE, standardized and integrated, as the outcome measure. In conducting this ANCOVA we adhered closely to Schneider, Avivi-Reich and Mozuraitis's (2015) set of recommendations. First, preliminary analyses were conducted to ensure there were no violations of the assumptions of normality, homogeneity of variance (Levene's test) and linearity between the covariate and the post-intervention CORE scores. Next, the covariate was 'centred'. Third, an ANCOVA was performed. The betweenparticipants main effect of Age (centred) and the within-participant Time by Age (centred) interaction effect were both evaluated using the ANCOVA output. Finally, an ANOVA was carried out by removing the covariate. The remaining main effects (Time, Group) and the Time $\mathrm{x}$ Group interaction were evaluated using the ANOVA output. Table 2 below provides 
the composite ANCOVA table.

Insert Table 2

about here

The main effect of Age (centred) $[F(1,82)=.19, p=.665]$, and the Age (centred) $\mathrm{x}$ Time interaction $[F(1,82)=.85, p=.359]$, both proved to be non-significant. This suggested that participants' ages did not affect their levels of distress, either before or after treatment. The main effect of Time was highly significant $[F(1,83)=67.48, \mathrm{p}=.001]$ with distress levels across participants significantly lower after treatment than before. The main effect of Group was non-significant $[F(1,83)=2.09, p=.152]$ suggesting there were no overall differences in distress levels between those in the integrated intervention and those in the counselling-only condition. However, this effect was moderated by Time such that the Group x Time interaction proved to be significant $[F(1,83)=9.54, p=.003]$. The nature of the interaction is presented in Figure 2 below and suggests that the reduction in distress is greater in the integrated intervention than counselling-only.

Insert Figure 2

about here 
To explore the interaction more fully, independent $t$ tests were carried out between groups before and after the intervention. At baseline, no differences in mean distress levels were noted between groups $[t(83)=-.10, \mathrm{p}=.921]$; at endpoint, mean distress levels were significantly lower in the integrated condition than the counselling-only condition $[t(83)=$ $2.44, p=.017]$. Therefore, there was a statistical difference between groups at the end of therapy such that participants in the integrated condition improved significantly more than those in the counselling-only condition on the standardized CORE measures, with an effect size $(d)$ of $0.53(95 \%$ CI: $0.09-0.96)$.

\section{Qualitative findings}

The five interview participants were allocated pseudonyms to maintain confidentiality and they will be known as Jade, Caitlin, Seth, Annie and Millie. A diagrammatic representation of themes can be seen in Figure 3. It should be stated at the outset that since PC is an integrated model that combines counselling and coaching, we are not in a position to decide which of the two components is uniquely responsible for the extracted themes.

Insert Figure 3

about here

\section{(1) Developing a sense of agency}


All participants developed awareness in sessions that they had control and volition over their lives. The following themes emerged:

Exercising own agency. All participants showed evidence of exercising their own agency in sessions either in relation to choosing their future career or changing aspects in their day-today life. For example, Jade explains that "it's more kind of you being honest about what you want to do other than what other people expect you to do and incorporating into kind of your wider picture and what you actually choose to do."

Overcoming difficulties. All participants talked about how the sessions helped them to overcome difficulties. Participants achieved this by finding practical solutions with their Personal Consultant, discussing the cause of the difficulty or the Personal Consultant probing them to find the answer within them. Annie highlights the difficulties that she has overcome: "I can talk to people a lot more even if it's really bad things, how to cope with losing someone, the signs of a good and bad relationship ... erm how to calm down and just ... how to be myself."

Moving forward. Four participants showed evidence of moving forward (making progress or change). Jade described how the sessions helped her do so:

[The sessions] ... allow me to kind of see things in a way that's more healthy and help me to move forward better, rather than just seeing it for the strong emotions like if you're just feeling really angry and frustrated you're just gonna continuously feel like that, rather than actually deal it and go forward.

Making own decisions. Three participants found that the sessions helped them to make decisions. There was an emphasis on owning their decisions and making their decisions on their own terms, rather than on other people's. For example, Seth described: "if you get that illusion that it's you that's actually come up with the idea, it feels ten times better than if 
you'd been forced to do it. Because it's your actual idea and you've thought of that." Setting goals. Two participants commented on how setting goals was part of their PC experience. Both participants evidenced a sense of pride when they achieved their goals. Caitlin elaborates on her experience of setting goals:

We did a future plan, so what we want from the future and what we can do now to change about the future and help me get to my goals .... So I've started being good at school, not bunking lessons, working hard, getting along with the teachers and stuff. Increase in motivation. Two participants found that their sessions increased their motivation and they are now more active as a result. Annie, for example, found that a proactive intervention (step ladder) enabled her to set goals which increased her motivation: "It was just things on there that I could do in my spare time cos I never used to do anything ... and made me feel better about myself."

This master theme demonstrates that all participants are realizing that they have more control over their lives and are beginning to increase their confidence in their ability to influence their environment to overcome challenges.

\section{(2) Management of affect}

All participants reported that the sessions have helped to manage their emotions in some way. More able to manage emotions. All participants claimed that they are more able to manage their emotions as a result of the sessions. The ways that participants achieved this seemed to be with either practical techniques or by coming to terms with the past. Caitlin elaborates on a practical technique that she was taught in session: "So when I was feeling down or something, I would just do that (pings band) and then, I wouldn't feel bad and not have scars and I wouldn't feel unwanted I would just be normal."

More able to manage anger. All clients reported that they are more able to manage their 
anger. This theme also infers that all clients experienced problems with anger prior to sessions. Participants reported that talking about their anger or finding practical ways to reduce their anger was helpful. Seth reflects on the change in his anger since the beginning of the sessions: "I've not really been angry that much, compared to what I used to be. I still get little outbursts. But ever since I've finished, I've been a lot more calmer than what I was before."

Venting/releasing build-up of emotions. Three participants found that the sessions helped to find more helpful ways to 'vent' or release the build-up of emotions. These included talking about their emotions or using active techniques. Millie explains how her Personal Consultant helped her to find active forms of venting: "She found things that I enjoyed but if I ever got like really wound up or anything, that I could use the thing I enjoyed as a way of venting if I didn't have anyone to talk to."

Improved mood after sessions. Two participants evidenced that their mood improved after sessions. Seth asserts: "But normally I'd feel a lot more perked up, a lot more energetic and like you said, more motivated to do work next lesson."

This master theme demonstrates that managing emotions was a significant aspect of the PC experience for participants. Both modes of 'doing with' and 'being with' were evidenced to contribute to this master theme.

(3) Making sense of past, present and/or future

All participants found that the sessions helped them to begin to comprehend their own past, present and future and how these phases of time are related.

Making a connection between past, present and future. Three participants stated that forming connections between the past, present and/or future helped them change a perspective which, in turn, led to changing some of their thoughts, emotions and behaviours. Jade asserts: 
They all obviously fit together it's one continuous time spectrum, and going through what happened in the past affected like how I felt in the present or about my future or about loads of different things kind of combined and it's important to like deal with one thing to deal with the next and deal with the now and deal with the future.

Developing a positive outlook of the future. Three of the five participants found that talking about the future, particularly their career plans, helped them to form a positive view of the future (which was previously negative for all of them). Jade demonstrates this:

It's [the future] kind of like this big scary dark cloud that's covering your sunny day, but then you have to think about it and it kind of helped me to put stuff in a kind of ... good sort of view where I could look at it properly and see it for what it was.

Gained understanding of the past. Three participants talked about how they now had a better understanding of their past and as a result are more able to move forward. Caitlin describes this process:

And I used to bottle it up and put it in a box and put it away and now we've started to open the boxes and put them where they need to go and forget about them and so I'm not stressed up about the past and things that could happen and stuff.

Reduced rumination of the past. Two clients talked of how they now focus less on the past due to the PC sessions. Seth asserts: "I've learnt to focus on like things like we have now, rather than things that happened in the past, yeah so my thoughts have changed quite a lot since I've had counselling and that."

This master theme indicates that an approach that can address both the past and the future and moving comfortably between time frames can be beneficial to young people. The evidence demonstrates the benefits for clients of focusing on 'existing patterns' in the past and present and 'emerging patterns' in the present and future that is emphasized in the PC 
model (Popovic \& Jinks, 2014). An integrated approach allows practitioners to move comfortably between time frames.

\section{(4) Enhancing interpersonal relationships}

All participants found that the sessions helped them to improve their interpersonal relationships.

Experiencing different ways of interacting with Personal Consultant. All of the young people reported that they could interact with their Personal Consultant in a different way to how they would interact with others. Some participants found that having opinions from their Personal Consultant was helpful, and all found that having someone to talk to about their concerns was helpful as they all had a shortage of people with whom they could discuss sensitive issues. Jade states that "Actually having someone who can put a professional opinion to it is a lot better than like family or something like that." All participants said that they had a good relationship with their Personal Consultant. Millie found that, as time went on, “eventually you can like you have a laugh with them [Millie's Personal Consultant] and genuinely enjoy the time that you have with them sorta thing".

Managing difficult relationships. Four clients claimed that the sessions helped to manage difficult relationships through a variety of different means. These ranged from learning to distinguish "the signs of a good and bad relationship" (Annie), learning compromise, understanding difficult relationships and realising that they have choice over their relationships. Caitlin elaborates on how this applied to her: "I realised that they're trying too and I have to meet them halfway, I can't make them do all the work and me just look back saying no, no. So I have to meet halfway and forget about things and then we can just hopefully move on." Able to choose more positive relationships. Two participants claimed that the sessions 
helped them to be able to choose more positive relationships. They learnt the signs of positive and negative relationships, which helped them to decide who to invest their time in. Amber found that "counselling sessions were on relationships and stuff .... and now I know how to choose the wrong from the right."

The sessions enabled participants to change perspective and gain insight on what they wanted and needed from relationships. They have started to make changes to manage difficult relationships and form more positive ones.

(5) Developing self

All participants found that PC aided growth of several aspects of themselves.

Gained focus. Four participants demonstrated that they had gained focus from the sessions. They were now able to be more productive, to think about their future and to generate solutions for specific issues. Jade explains that "focus is good I think yeah that's definitely a thing cos a lot of the time for me personally I brought up ... just everything at once like it's one big constant whirlwind so it's difficult to just step back and focus about one thing on its own."

Forming identity. Three participants showed evidence of the sessions helping them to form and shape their identity. Millie elaborates on how this applies to her: "Yeah I'm still not exactly a people person and everything but people take it the wrong way but like ... but you just talk about it and you just sorta learn like not to really see it as a bad thing that people like see you in a bad way just cos you're not like what they are."

Increased openness. Three participants showed increased openness with people either in and/or outside sessions as a result of their PC. All participants previously found it difficult to be open. Seth found "that you could actually open up so and there was no need to feel nervous about it. You just relaxed and talked." 
Gaining perspective. Three participants indicated that the sessions were helpful in gaining perspective. It seems that this was achieved just by the act of talking things through and by the prompting and questioning of the Personal Consultant. Millie found that "looking at it from my view, and other people's view and then ... for knowing that there's more to one side, cos you're understanding that there's more than one side to it, sort of makes you feel better about it."

Building up confidence. Two participants demonstrated that they had built up confidence during the sessions. They claimed that learning practical skills to bolster confidence in managing specific situations or achieving goals in sessions aided this. Millie found that "you get taught ways how to cope with it and .... you just sort of like build up confidence in yourself ... like then you know you can deal with it."

Changing thought processes. Two participants reported that the sessions helped to change thought processes. Jade found that the Personal Consultant's reactions to her thoughts helped her to reflect, gain perspective and then change them:

It's very different thinking something than saying something, cos like when you say it you get a reaction and when you think it it's just your own internal reaction and you're not really processing it properly. But then when you kind of, when you kind of actively talk about it, you realised certain things and like people's reactions help shape what you're thinking and like why you're thinking it and what you should be thinking I suppose and stuff like that.

This master theme indicates that PC helps several aspects of self-development of young people. Both modes of 'doing with' the client and 'being with' the client contributed to the evidence of this master theme.

\section{Discussion}


The hypothesis that participants in the integrated condition would show greater improvement than counselling-only counterparts was supported by the quantitative component of the research. Specifically, distress levels reduced from 'moderate-severe' to 'mild' for those in the integrated condition and from 'moderate-severe' to 'moderate' among those in the control condition. The effect size may be interpreted as 'medium' (Cohen, 1988) and is comparable to those of other psychological therapies delivered to adults and children (Kazdin, 2004; Lambert \& Ogles, 2004), and to young people in school-based humanistic counselling services (Cooper et al., 2013; Pybis et al., 2014).

As far as we know, this is the first study to demonstrate empirically the salutary effects of the integrated approach among young people and to note its added value over a standard counselling intervention. We have used the qualitative material in order to explore possible reasons for these results.

Five master themes were extracted from the qualitative data: making sense of past, present and/or future, developing a sense of agency, management of affect, enhancing interpersonal relationships and development of self. The themes extracted demonstrate the positive experience for young people in addressing intra-psychic issues and personal conflicts on one hand (a reflective and restorative approach designed to bring about internal change), and present and future challenges of growing-up on the other (a developmental and futurefocused approach designed to achieve external change). The extent to which these themes may be attributable to coaching or counselling is impossible to determine given the integrative nature of the intervention.

The most prevalent master theme to emerge from the interview data was the development of a sense of agency. This master theme relates to the experiences of participants in sessions that led to a growing realisation that they had some control over their 
lives. Clients emphasised this theme and seemed to value its content, which is in line with coaching research with young people (Green, Grant \& Rynsaardt, 2007). There are a number of connections between this master theme and other emergent themes. For example, the majority of participants described that gaining focus (subtheme of developing self) led them to have an increase in motivation (subtheme of developing a sense of agency). Exercising one's own agency (subtheme of developing a sense of agency) also seems to play a part in managing difficult relationships and being able to choose more positive relationships (subthemes of enhancing interpersonal relationships). Overcoming difficulties (subtheme of developing a sense of agency) seems to be interconnected with being more able to manage anger (subtheme of management of affect) and difficult relationships too (subtheme of enhancing interpersonal relationships). Finally, the master theme of developing a sense of agency is connected to the master theme of enhancing interpersonal relationships as the young people realise that they have the agency to affect relationships. Recognising that all themes are not isolated and distinct, but interconnected and relational is important as they can influence each other in constructive and maladaptive ways. This also allows a more comprehensive picture of the overall experience of PC.

\section{Limitations}

There were some important limitations to this study that must be acknowledged. First, although the mean number of sessions was similar between groups, nevertheless there was variability in the number of sessions within each group. Perhaps an extended data collection window would have overcome this. Second, there was no auditing or monitoring of practice, outside of monthly supervision, such that it was not possible to verify fully that counsellors were, indeed, delivering the integrated approach that they had been trained in, supervised in, and had agreed to deliver. Third, key client information, such as presenting problems, ethnic 
background, religion or belief, or disability information, was not captured. Hence, although their overall levels of psychological distress were known, there was no insight into participants' specific problems and the extent to which diversity influenced outcomes. Fourth, though research was conducted at four independent agencies, the sample size was too small to explore whether the beneficial effects of the integrated group were detectable in each agency. In addition, the small sample size for the qualitative interviews limits the generalisability of the findings. Fifth, as the allocation of participants to intervention condition was not randomized, we are limited in making causal claims regarding the effect found with the integrated treatment. Furthermore, we are unable to infer whether the effect would likely be found in the population. There was loss of experimental control regarding allocation to groups such that some participants were inadvertently presented with a choice over their treatment while others were not. Sixth, although the CORE-10 and the YP-CORE scales are very similar in content, the final question in each measure is noticeably different $[I$ have felt panic or terror (CORE-10); I've done all the things I wanted to do (YP-CORE)]. It may be argued that creating total scores for each measure that are then standardized to facilitate comparison is not an ideal procedure. To address this issue we omitted these questions from the total scores and re-analysed the data (based on each scale containing nine items). Controlling for group differences in age, the same results were found such that the integrated model yielded a better outcome than the counselling-only intervention [Group $\mathrm{x}$ Time interaction: $F(1,83)=6.90, p=.010]$. Seventh, there was a lack of independent data collection. It would have been better if the people who gathered the before and after measures of wellbeing were different from those who delivered the interventions. Eighth, we are unable to claim whether the qualitative themes reflect the coaching or counselling elements of the PC model. Finally, it could be argued that the benefits of the counselling- 
only intervention may take longer to come to fruition and therefore a follow-up study might yield convergence between groups. There are no plans in place at present to carry out a follow-up study of these participants but this and the other limitations are duly noted.

\section{Future Research}

As this is the first study to test the utility of the PC model, replication studies are clearly needed. Ideally, these would involve larger, more age equivalent, sample sizes, and randomized controlled studies including waitlist control groups. Tailoring the integrated intervention in other youth contexts such as medium-term unemployment, a client group who may present with symptoms of distress but also may choose to work on goal-orientated issues, may be beneficial. Procedures to record and audit counselling sessions, so that fidelity to the model of practice can be assessed, would also be desirable. Independent assessment at baseline and endpoint would strengthen the reliability of the findings, as would a more formal appraisal of presenting problems. Assessment of outcomes at six months or one-year follow-up would be particularly helpful in establishing the long-term effects of the integrated treatment and would also provide an adequate amount of time for the benefits of the counselling-only intervention to fully accrue. Such outcome measures could be more extensive too. For example, the CORE-OM measure contains subscales that assess psychological functioning, symptoms, risk and well-being. Incorporating an equivalent measure for young people would help to identify those aspect(s) of well-being that might benefit most from the integrated intervention. Furthermore, variables such as self-efficacy, hope, or changes in locus of control, should be included in order to test their mediating effects on the association between intervention condition and well-being. Insights into the mechanisms of change could also be generated via a dismantling study. The working alliance was not monitored in the quantitative component and could be evaluated further. The 
qualitative evidence indicates that, overall, the therapeutic alliance was positive for all participants interviewed.

\section{Conclusions}

At a time when pressures on young people are greater than ever, and services to support them are subject to cuts across all sectors, new cost-effective interventions to help young people are needed (Mumby, 2014). The model of PC that integrates counselling and coaching meets this challenge particularly well through creating an opportunity for both psychological provision and support for behavioural change and goal attainment. This study demonstrated the differential benefits of a PC approach with distressed young people compared with a standard counselling approach. It also confirmed that the participants experienced the intervention positively and they reported cognitive, behavioural and affective changes in response. However, these conclusions must be tempered by the limitations that were encountered in the execution of the study. Overall, integrative counselling and coaching has shown to be an effective treatment that can lead to a reduction in young people's psychological distress and that can support them in making constructive changes. 


\section{Acknowledgements}

The authors would also like to acknowledge and thank all the staff and service users involved at each of the agencies, Off The Record Youth Counselling Croydon, Isle of Wight Youth Trust, Interchange Sheffield Community Interest Company, and No Limits (Southampton). Thanks to Carolyn Mumby and Barbara Rayment who made the implementation of this project possible. 


\section{References}

BACP. (2016). Position statement. Retrieved July $1^{\text {st }} 2016$ from

\section{http://bacpcoaching.co.uk/position-statement}

Bachkirova, T. \& Cox, E. (2004). A bridge over troubled water: Bringing together coaching and counselling. The International Journal of Mentoring and Coaching, 2(1), 1-10.

Barkham, M., Bewick, B., Mullin, T., Gilbody, S., Connell, J., \& Cahill, J. ... \& Evans, C. (2013). The CORE-10: A short measure of psychological distress for routine use in the psychological therapies. Counselling and Psychotherapy Research, 13(1), 3-13. http://dx.doi.org/10.1080/14733145.2012.729069

Beck, A. T. (1978). Depression inventory. Philadelphia: Centre for Cognitive Therapy.

Berg, I., \& Steiner, T. (2003). Children's solution work. New York: Norton.

Buckley, A. (2007). The mental health boundary in relationship to coaching and other activities [Special Issue No. 1], International Journal of Evidence Based Coaching and Mentoring, 11-23.

Children's Society. (2008). The Good Childhood Inquiry: Health research evidence. London: Children's Society.

Cohen, J. (1988). Statistical power analysis for the behavioral sciences (2nd ed.). Hillsdale, NJ: Lawrence Earlbaum Associates.

Connell, J. \& Barkham, M. (2007). CORE-10 User Manual, Version 1.1. CORE System Trust \& CORE Information Management Systems Ltd.

Cooper, M., (2004). Counselling schools project: Evaluation report. Glasgow: Counselling Unit, University of Strathclyde.

Cooper, M. (2009). Counselling in UK secondary schools: A comprehensive review of audit 
and evaluation data. Counselling and Psychotherapy Research, 9(3), 137-150. http://dx.doi.org/10.1080/14733140903079258

Cooper, M., Pybis, J., Hill, A., Jones, S., \& Cromarty, K. (2013). Therapeutic outcomes in the Welsh Government's school-based counselling strategy: An evaluation. Counselling and Psychotherapy Research, 13(2), 86-97. doi:10.1080/14733145.2012.713372

Derogatis, L. R. (1994). Symptom Checklist-90-R: Administration, Scoring, and Procedures manual (3rd ed.). National Computer Systems, Inc.; Minneapolis, USA.

Evans, C., Mellor-Clark, J., Margison, F., Barkham, M., McGrath, G., Connell, J. \& Audin, K. (2000). Clinical Outcomes in Routine Evaluation: The CORE-OM. Journal of Mental Health, 9, 247-255.

Geldard, G. \& Geldard, K. (2010). Counselling adolescents: The proactive approach for practice (3rd ed.). London: Sage.

Giant, N. (2014). Life coaching for kids. London: Jessica Kingsley.

Green, L. S., Grant, A. M., \& Rynsaardt, J. (2007). Evidence based life coaching for senior high school students: Building hardiness and hope. International Coaching Psychology Review, 2, $24-32$.

Griffiths, K. \& Campbell, M. A. (2008) Semantics or substance? Preliminary evidence in the debate between life coaching and counselling. Coaching: An International Journal of Theory, Research and Practice, 1(2), pp. 164-175.

House of Commons Health Committee. (2014). Children's and Adolescents' CAMHS, Third Report of Session 2014-2015. London: The Stationery Office Limited. Retrieved from

http://www.publications.parliament.uk/pa/cm201415/cmselect/cmhealth/342/342.pd 
Kazdin, A. (2004). Psychotherapy for children and adolescents. In M. Lambert, Bergin and Garfield's handbook of psychotherapy and behaviour change (5th ed., pp. 543-549). New York: Wiley.

Kessler, R., Berglund, P., Demler, O., Jin, R., Merikangas, K., \& Walters, E. (2005). Lifetime Prevalence and Age-of-Onset Distributions of DSM-IV Disorders in the National Comorbidity Survey Replication. Archives of General Psychiatry, 62(6), 593. http://dx.doi.org/10.1001/archpsyc.62.6.593

Kessler, R. C., Amminger, G. P., Aguilar-Gaxiola, S., Alonso, J., Lee, S., \& Ustun, T. B. (2007). Age of onset of mental disorders: A review of recent literature. Current Opinion in Psychiatry, 20(4), 359-364. http://doi.org/10.1097/YCO.0b013e32816ebc8c

Kim-Cohen, J., Caspi, A., Moffitt, T., Harrington, H., Milne, B., \& Poulton, R. (2003). Prior Juvenile Diagnoses in Adults with Mental Disorder. Arch Gen Psychiatry, 60(7), 709. http://dx.doi.org/10.1001/archpsyc.60.7.709

Lambert, M. J., \& Ogles, B. M. (2004). The efficacy and effectiveness of psychotherapy. In M. J. Lambert (Ed.), Bergin and Garfield's handbook of psychotherapy and behavior change (5th ed., pp. 139-193). New York: Wiley.

Lynass, R., Pykhtina, O., \& Cooper, M. (2012). A thematic analysis of young people's experience of counselling in five secondary schools in the UK. Counselling and Psychotherapy Research, 12(1), 53-62.

http://dx.doi.org/10.1080/14733145.2011.580853

Maxwell, A. (2009). The co-created boundary: Negotiating the limits of coaching. International Journal of Evidence Based Coaching and Mentoring, 3, 82-94. 
Mumby, C. (2011). Working at the boundary. BACP Counselling Children and Young People Journal. December, 14-19.

Mumby, C. (2014). Personal Consultancy with young people. In N. Popovic, \& D. Jinks, (Eds.), Personal Consultancy: A model for integrating counselling and coaching (pp.139-160). London: Routledge.

Nuffield Foundation. (2013). Social trends and mental health: Introducing the main findings. London: Nuffield Foundation.

ONS. (2016). Measuring national well-being: Life in the UK: 2016. Retrieved from http://www.ons.gov.uk/peoplepopulationandcommunity/wellbeing/articles/measurin gnationalwellbeing/2016

Passmore, J., \& Brown, A. (2009). Coaching non-adult students for enhanced examination performance: A longitudinal study. Coaching: An International Journal of Theory, Research and Practice, 2(1), 54-64. http://dx.doi.org/10.1080/17521880902783124

Patrick, E. (2015). An 'effecticient' intervention. BACP Children and Young People. September 2015, 36-39. Retrieved from http://bacpcoaching.co.uk/ sitedata/1407851323\%209rTpdfnye/An\%20effecticient \%20intervention.pdf

Pointon, C. (2003). 'A life coach in 2 days'. Counselling and Psychotherapy Journal, 14(10), 20-24.

Popovic, N., \& Boniwell, I. (2007) Personal Consultancy: An integrative approach to one to one talking practices. International Journal of Evidence Based Coaching and Mentoring. [Special Issue No. 1], 24-29.

Popovic, N., \& Jinks, D. (2014). Personal Consultancy: A model for integrating counselling and coaching. London: Routledge. 
Pybis, J., Cooper, M., Cromarty, K., Hill, A., Levensley, R., Murdoch, J., \& Turner, N. (2014). Pilot randomised controlled trial of school-based counselling for psychological distress in young people: Outcomes and methodological reflections. Counselling and Psychotherapy Research. doi:10.1080/14733145. 2014.905614

Schneider, B. A., Avivi-Reich, M., \& Mozuraitis, M. (2015). A cautionary note on the use of the Analysis of Covariance (ANCOVA) in classification designs with and without within-subject factors. Frontiers in Psychology, 6, 474.

http://doi.org/10.3389/fpsyg.2015.00474

Shaya, F. T., \& Gu, A. (2007). Critical assessment of intent-to-treat analyses. Journal of Medical Economics, 10(2), 171-177.

Simons, C. (2006). Should there be a counselling element within coaching? The Coaching Psychologist, 2(2), 22-25.

Smith, J. \& Osborn, M. (2003). Interpretive phenomenological analysis. In J.A. Smith (Ed.) Qualitative psychology: A practical guide to research methods (pp.51-80). London: Sage.

Smith, J. A., Flowers, P. \& Larkin, J. (2009). Interpretative Phenomenological Analysis: Theory, Method and Research. London: Sage.

Spinelli, E. (2008). Coaching and Therapy: Similarities and divergences. International Coaching Psychology Review, 3(3), 241-249.

Street, C. (2014). Children and Young People's Views of Counselling: Improving the Tools to Gather Outcomes[pdf]. Youth Access. Retrieved from http://www.youthaccess.org.uk/uploads/documents/Children and Young Peoples v iew_on_Counselling-_March_2014_1.pdf

Twigg, E., Barkham, M., Bewick, B. M., Mulhern, B., Connell, J., \& Cooper, M. (2009). The 
Young Person's CORE: Development of a brief outcome measure for young people. Counselling and Psychotherapy Research, 9, 160-168. doi:10.

$1080 / 14733140902979722$

Westergaard, J. (2013). Counselling young people: Counsellors' perspectives on 'what works' - An exploratory study. Counselling and Psychotherapy Research, 13(2), 98105. http://dx.doi.org/10.1080/14733145.2012.730541

Williams, P. (2003), The potential perils of personal issues in coaching. The continuing Debate: Therapy or coaching? What every coach must know! International Journal of Coaching in Organizations, 2003 2(2): 21-30

Youth Access, (2015). Youth access: An integrated health and wellbeing model. Youth Access. Retrieved from http://www.youthaccess.org.uk/uploads/documents/YIACS_an_integrated health_a $\underline{\text { nd wellbeing model.pdf }}$

Youth Access, (2016). About youth access. Retrieved from http://www.youthaccess.org.uk/about-youth-access/ 
Table 1. Mean levels of self-reported distress as a function of time and intervention group (SD in parentheses).

\begin{tabular}{ccccc}
\hline & \multicolumn{2}{c}{ Integrated } & \multicolumn{2}{c}{ Counselling } \\
& \multicolumn{2}{c}{$(n=42)$} & \multicolumn{2}{c}{$(n=43)$} \\
\cline { 2 - 5 } & Baseline & Endpoint & Baseline & Endpoint \\
\cline { 2 - 5 } CORE & & & & \\
& 20.31 & 11.95 & 20.16 & 16.37 \\
& $(6.96)$ & $(7.93)$ & $(6.65)$ & $(8.75)$ \\
\hline
\end{tabular}

Note: Baseline $=$ baseline assessment; Endpoint $=$ endpoint assessment; $\mathrm{CORE}=$ amalgamated scores for CORE-10 and YP-CORE; Lower scores indicate better outcomes on the CORE. 
Table 2. Composite ANCOVA table for CORE scores at baseline and endpoint.

\begin{tabular}{llllll}
\hline Source & $\begin{array}{l}\text { Type III Sum of } \\
\text { Squares }\end{array}$ & $d f$ & $\begin{array}{l}\text { Mean } \\
\text { Square }\end{array}$ & $F$ & Sig \\
\hline TESTS OF WITHIN-SUBJECT EFFECTS & 19.83 & 1 & 19.83 & 0.85 & .359 \\
\hline Time*AgeCentred (from ANCOVA) & 1908.55 & 82 & 23.28 & & \\
Error term (from ANCOVA) & 1567.72 & 1 & 1567.72 & 67.48 & .001 \\
Time (from ANOVA) & 221.53 & 1 & 221.52 & 9.54 & .003 \\
Time*Group (from ANOVA) & 1928.38 & 83 & 23.23 & & \\
Error (from ANOVA) & 17.70 & 1 & 17.70 & 0.19 & .665 \\
\hline TESTS OF BETWEEN-SUBJECTS EFFECTS & 7692.71 & 82 & 93.81 & & \\
\hline AgeCentred (from ANCOVA) & 193.97 & 1 & 183.64 & 2.09 & .152 \\
Error (from ANCOVA) & 7710.41 & 83 & 92.90 & & \\
Group (from ANOVA) & & & & & \\
Error (from ANOVA) & & & & & \\
\hline
\end{tabular}


Figure 1. The stages and dimensions of the PC model.

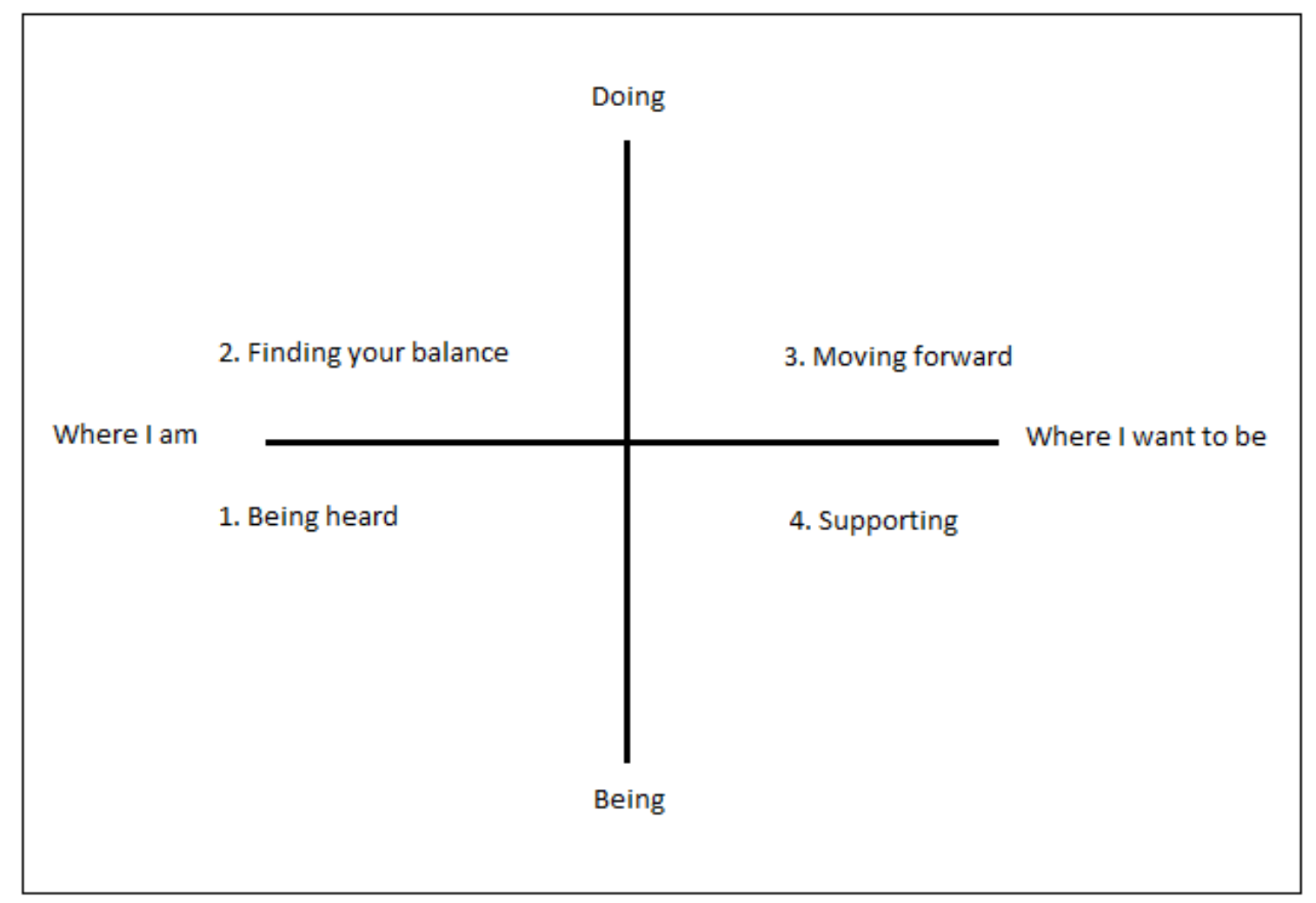


Figure 2. Mean CORE distress scores as a function of time and intervention group.

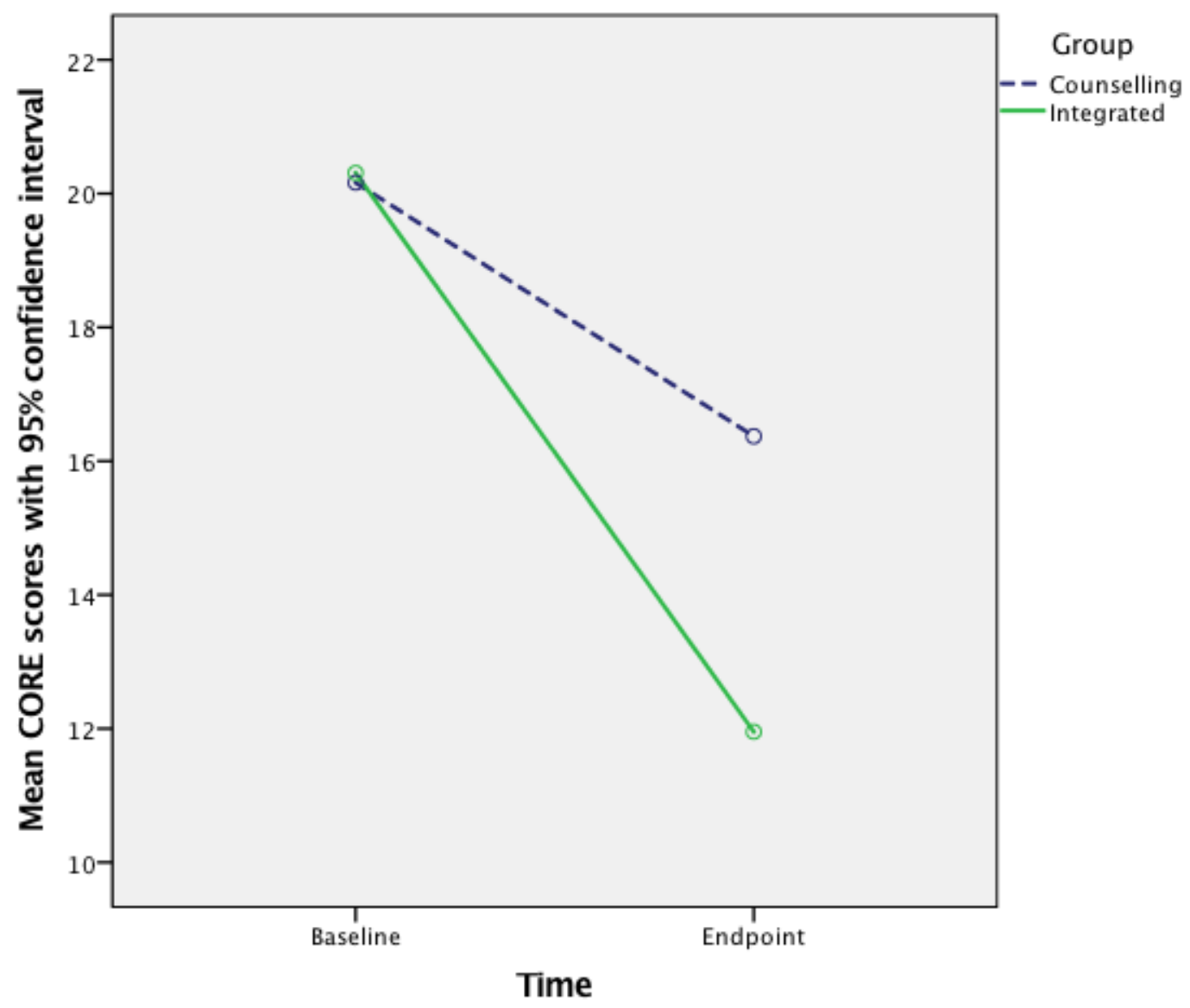


Figure 3. A diagrammatic representation of themes.

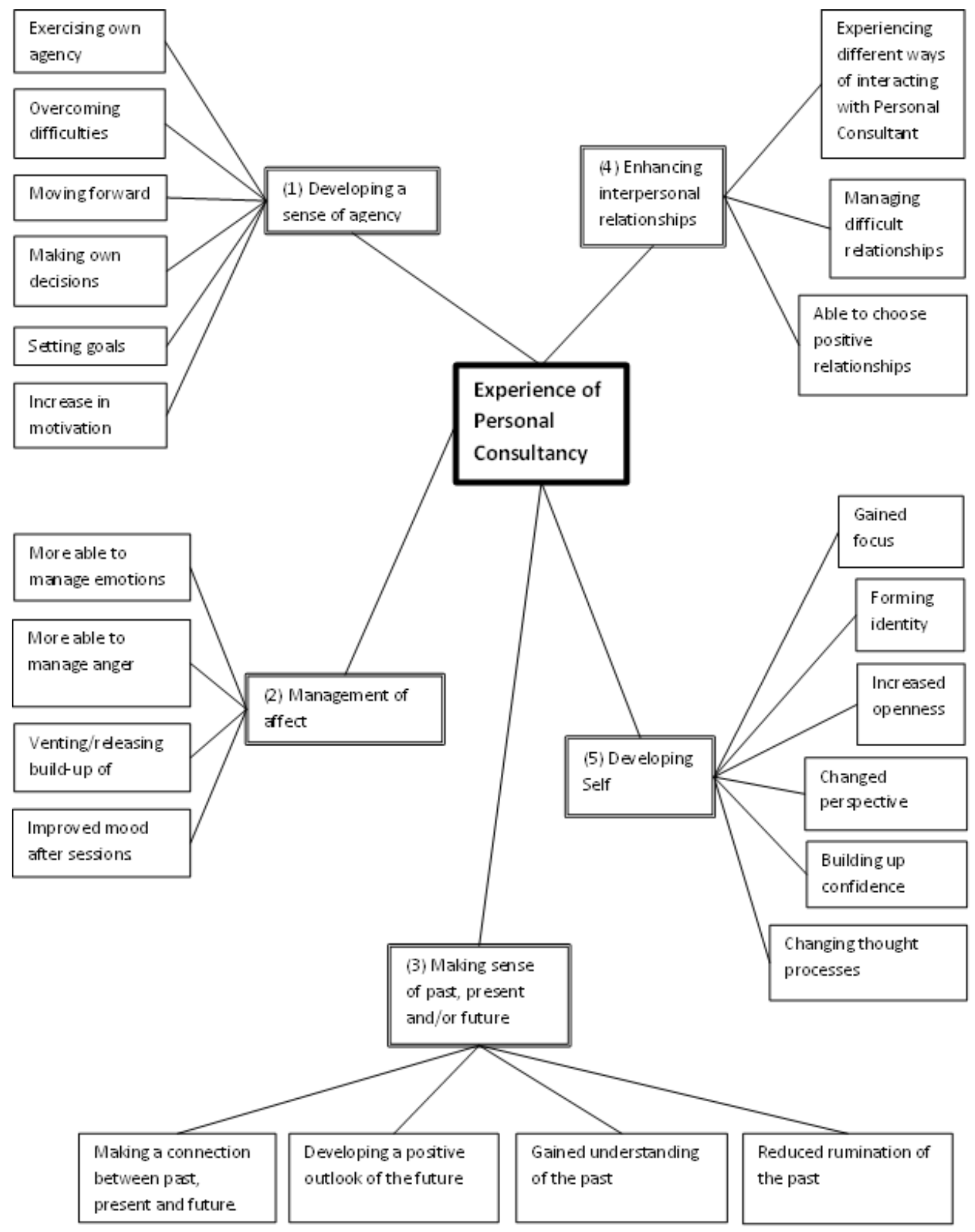

